\title{
Cosmic Space in Zero-Dimension: A Discussion on Spatial Question According to the M-Theory
}

\author{
Samo Liu ${ }^{1,2}$ \\ ${ }^{1}$ HMR Technology Holdings Group, Jinan, China \\ ${ }^{2}$ University of Science and Technology Beijing, Beijing, China \\ Email: samo945@126.com
}

How to cite this paper: Liu, S.M. (2021). Cosmic Space in Zero-Dimension: A Discussion on Spatial Question According to the M-Theory. Open Journal of Philosophy, 11, 159-170.

https://doi.org/10.4236/ojpp.2021.111012

Received: January 19, 2021

Accepted: February 5, 2021

Published: February 8, 2021

Copyright (c) 2021 by author(s) and Scientific Research Publishing Inc. This work is licensed under the Creative Commons Attribution International License (CC BY 4.0).

http://creativecommons.org/licenses/by/4.0/ (c) (i) Open Access

\begin{abstract}
This work will examine the hypothesis that the Essence of the Universe is a dimensionless zero-dimension using a combination of Eastern philosophical ideologies and theories in modern physics. The author proposes that all existence is energy-based, divided into yin and yang, and more specifically, he names them the Intelligent Energy and Fundamental Energy. These two types of energy are simultaneously the existence and existence's dynamic, and when combined, these energies created the three-dimensional Universe. Under the action of information, they perform exchanges and circulation with all physical substances.
\end{abstract}

\section{Keywords}

Zero-Dimensional Space, Fundamental Energy, Intelligent Energy,

Three-Dimensional Space, Matter, Information, Energy

\section{Introduction}

The great mathematician Gottfried Wilhelm Leibniz (1646-1716) had a philosophical thought that he discussed in his correspondence with Samuel Clarke about questions on space that "what Substance will that bounded empty space be an affection or property of, [...] suppose to be between two bodies?" (Leibniz, 2000) What truly is the empty space that Leibniz described? It is a vacuum, nor quantum vacuum? No, it should be a space deprived of everything, including particles and any other beings and it is rather challenging to describe this space which is with present concepts. By referencing theories from modern physics, including materials, information, and energy, and combining with the Oriental knowledge and philosophical thinking from the Axial Age, this work tentatively explores the hypothesis that space is zero-dimensional, and it is where the Es- 
sence of the Universe in which the myriad things include particles, materials, and all living being originated (Jaspers, 1953; Liu, 2020c). Every substance in the Universe is three-dimensional, except for space itself, which is zero-dimensional. Matter and space are two different concepts that philosophy, science, and religions should clearly distinguish.

\section{Literature Review}

The core focus of Eastern philosophy has always been the question of what is the nature of space, what is the existence of time, what is the relationship between substances and space, and what is the relationship between humankind and the Universe (Liu, 2020b). The following section will explore the teaching and enlightenment on the Essence of the Universe in ancient Chinese philosophy works, starting from I Ching, the predecessor of all Chinese philosophy works, followed by works from early Chinese history and finally to late works during the Song and Ming Dynasty.

\section{The Perception of Space Taught in I Ching}

The philosophical perception of the Universe by Eastern philosophy, or the Oriental knowledge, started with the ancient Chinese work I Ching. The original I Ching had only two symbols, that of yin and yang (Hu, 2012; Zhu, 2020). In modern computer language, this is equal to the symbols 0 and 1 , or + and -. In $I$ Ching, yin was portrayed by a solid dot or two short dashes, and on other hand, yang was portrayed by a hollowed circle or a solid dash (Figure 1).

I Ching gave a general framework on the Truth of the Universe, that the Universe is formed by yin and yang that encompassed all existence and dynamic that also contained yin and yang ( $\mathrm{Zhu}, 2020)$. Legend has that after the invention of language, writing, and numbers, the Eastern civilization developed the works Lianshan, Guicang, and Zhouyi. However, the first two books, Lianshan and Guicang, have been lost throughout history. From hints scattered throughout other ancient Chinese works, researchers speculated that Lianshan explored the relationship between substances and the Universe, and Guicang explored the relationship between humankind and the Universe (Liu, 2020c; Liu, 2020d). Only the book Zhouyi has been passing down throughout the generations in which historically, people used it for divination and oracle purposes ( $\mathrm{Hu}, 2012)$. Only a handful of scholars had studied the philosophical knowledge embedded within it that reflects upon the relationship between space and time to explore the Essence of humankind and the Universe (Liu, 2020c; Liu, 2020d).

\section{The Perception of Space Taught in Early Chinese Philosophy}

During the Axial Age, scholars around the around had made countless thinking and assumptions on space and time, which, unquestionably, was the best period to reflect over the Universe. Amongst vast numbers of ideologies on space and time, the most systematic ideology is the Chinese Daoism, created by the great sage Lao Zi. (c. 571-471 BC) Lao Zi’s work Dao De Jing has a famous quote on space and time: "The Dao that can be described is not the eternal Dao. The 


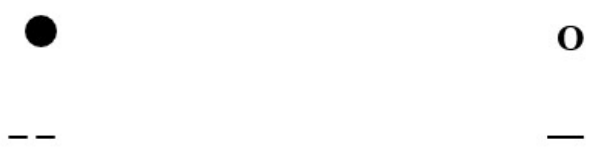

Figure 1. The symbols of yin and yang.

name that can be spoken is not the eternal Name. The nameless is the boundary of Heaven and Earth. The named is the mother of creation" (Laozi, 2015). Laozi believed that the Way of the Universe cannot be described accurately using human language and that even one tried hard to narrate the Way in writings, one can never fully transmit the Way behind it (Hu, 2012; Laozi, 2015). Laozi firmly believed that the nameless, otherwise known as the void or the zero-dimensional space, was the beginning of Heaven and Earth, or the Essence of the Universe (Laozi, 2015). On the other hand, he believed that the named, otherwise known as substances and three-dimensional space, was the mother of creation that formed the myriad things in the Universe following the motion and changes of yin and yang (Laozi, 2015).

Laozi had numerous disciples, three of the most prominent disciples were Wenzi (? - ?), Liezi (c. 450-375 BC), and Zhuangzi (c. 369-286).

In his work Wenzi, also known as Tongxuan Zhenjing (通玄真经, Classic of Understanding the Mysteries), Wenzi gave two significant concepts to the Essence of the Universe. The first concepts described the question of spacetime, in which Wenzi became the first person with recorded works attempting to define the Universe as a combination of space and time. The original segment in his writings was: The Universe refers to time and space, the Way is therein, but no one knows its location (Cleary, 1992). Here, Wenzi used the Chinese words Yuzhou, where $Y u$ was used to describe the space that included the sky and earth, and the world surrounded it, and Zhou used to describe the time that encompassed the past, present, and future. The second important contribution of Wenzi was that he interpreted and complemented the concept of "The nameless is the boundary of Heaven and Earth. The named is the mother of creation" that Laozi proposed in his Dao De Jing (Cleary, 1992; Laozi, 2015).

Qi was a Chinese Daoism concept on the description of the Essence of the Universe. Similar concept existed in Ancient Greek philosophy, namely the theory of Anaximenes of Miletus that air was the creator of all things and life (Allen, 2013; Thilly, 1914). However, since centuries, the concept of $q i$ was mistakenly taken as some being similar to air until the appearance of the famous Einstein's equation of relativity, $E=m c^{2}$ that people finally tried to explain $q i$ as a concept of energy (Liu, 2017).

Liezi, another prominent scholar after Laozi during the Warring States period in Ancient China, in his work Liezi, also known as Chongxu Zhenjing (冲虚真 经, Classic of Simplicity and Vacuity), Liezi also made two important contributions to the perception of the Universe. The first was on the questions of change in the Universe. Liezi believed that the only eternal and unchanged thing in the 
Universe was the eternal change happening in the Universe (Graham, 1990). This ideology of Liezi was an annotation to I Ching's perception of the Essence of the Universe (Allen, 2013). He believed that the $q i$ of yin and yang rendered the Universe a perpetual motion being such that matters undergo an eternal cycle of birth-rebirth and changes (Graham, 1990).

The second contribution of Liezi was on the perception and deduction of the chaotic period of the Universe. He believed that this period of chaos, which approximately corresponds to the Big Bang, was the critical moment that the Universe transitioned from zero-dimensional to three-dimensional (Graham, 1990). Liezi was the earliest person in recorded history to have divided the creation of the Universe into stages, and according to Liezi, the Universe experienced these four stages during the transition, namely the Primal Simplicity, Primal Commencement, Primal Beginnings, and Primal Material (Graham, 1990; Liu, 2020c). In his works, Liezi described these four stages as the following: The Primal Simplicity preceded the appearance of the breath. The Primal Commencement was the beginning of the breath. The Primal Beginnings were the breath beginning to assume shape. The Primal Material was the breath when it began to assume substance. Breath, shape and substance were complete, but things were not yet separated from each other; hence the name "Confusion" (Graham, 1990). Here, the breath, or $q i$, represents cosmic energy.

Zhuangzi, in his work Zhuangzi, also known as Nanhua Zhenjing (南华真经, True Scripture of Southern Florescence), Zhuangzi reflected profoundly on the Essence of the Universe and used then-available knowledge of the world, without the aid of modern physics knowledge, to describe the questions on the Essence of the Universe.

In the perception of the cosmic space, Zhuangzi believed that the Essence of the Universe was "so great that there is nothing outside it and so small that there is nothing inside it" (Legge, 1891a). This statement indicated that the Universe is zero-dimensional. It is because of this zero-dimensionality of the cosmic space that the myriad things created within this Universe, including galaxies, could be infinitely many. Also, the Universe and its three different dimensions can accommodate as many substances as it is available regardless of their size. Likewise, quasi-infinitely small substances could equally exist, to a limit, defined by professor Planck's (German physicist 1858-1947 AD) constant, delimiting the dimension and size limit of any substance before it underwent a transition from quantitative changes to qualitative changes.

To describe the Universe, Zhuangzi went further than the description of the spacetime given prior by Wenzi. Although Zhuangzi still believed that the Universe was made of space and time, he proposed that the cosmic space was the void that can only encompass energy $(q i)$ and substances that could not exist separately (Legge, 1891a). Zhuangzi believed that time existed only to record the change of substances throughout their existence, and not as a separate entity, and that time was a vector that could only advance (Legge, 1891a). He explained this theory in his work Zhuangzi-Geng-sang Chu: "He has a real existence, but it 
has nothing to do with place, such is his relation to space; he has continuance, but it has nothing to do with beginning or end, such is his relation to time"

(Legge, 1891a).

\section{The Perception of Space Taught in Late Chinese Philosophy}

After Wenzi, Liezi, and Zhuangzi, numerous other scholars had explored the Essence of the Universe. Amongst the famous prominent were: Song Jian (c. 370-c. 291 BC), Heguanzi (Warring States period), Zhang Zai (1020-1077), Zhu Xi (1130-1200), and Wang Yangming (1472-1529) (Liu, 2020d).

Zhang Zai, a Song dynasty philosopher that left the well-known saying of "To build up the manifestations of heaven and earth's spirit, to build up a good life for the populace, to develop past sages' endangered scholarship, and to open up eternal peace." He became a prominent scholar and set the foundation for the ideology on the Essence of the Universe in Oriental knowledge.

In his work Zhangzi Zhengmeng, Zhang Zi explored the philosophical basis of the later theory of relativity. He believed the main body and the Essence of the Universe was $q i$, a concept of energy (Zhang, 1978). Zhang Zi proposed that $q i$ had two geometrical forms: The first form is a zero-dimensional $q i$ called taixu (太虚, Primal Void), or wuwu (无无, Nothing in Nothingness), which is deprived of any concept of substances.

Zhu Xi, a Chinese philosopher from the Song dynasty, has written numerous works such as the Original Connotations of Yi and Commentary on Taiji Diagram that studied the principles of the Universe. His most famous theory was lixue, or the school of Principle. The main reasoning behind his speculation was that $q i$ (energy concept) had the parameters of yin and yang that led to the creation of myriad things (Zhu, 2020). However, why did the myriad things become diverse and not remained a single type of substance? (Zhu, 2020). Zhu Xi explained that the Universe was composed of a taiji of parameters yin and yang and that a principle existed for the Universe (Zhu, 2020). Similarly, the myriad things had their respective taiji of yin and yang and their principle. He subsequently isolated this concept of principle and taiji as an independent principle instead of a mechanism describing the dynamics of the Universe. He then used this concept to explain the reason and cause behind the existence and dynamics of the Universe and the myriad things that ultimately explained why the myriad things were created the way they were and their eternal motions and changes.

The theory of $l i$ was a significant contribution to Oriental knowledge in the exploration of the dynamics of the Universe. It explained that yin and yang were at the time contradicting and unifying and that it was also the essence behind the dynamics of the Universe. Zhu Xi also proposed in his theory of $l i$ that everything, including the void, the zero-dimensional Universe, and the myriad three-dimensional things, was under the constant contradiction of yin and yang, movement, and change. This process formed a cycle of contradiction $\rightarrow$ balance $\rightarrow$ loss of balance $\rightarrow$ contradiction (Zhu, 2020). This cycle is the natural cycle of the Universe (Zhu, 2020). Only the soul and the consciousness of humankind can recognize this cycle and solve the contradictions within it, ultimately renders 
humans the God within the Universe.

Wang Yangming, a Chinese philosopher and military general from the Ming dynasty, author of Chuanxilu (传习录, Instructions for Practical Living), promoted the xinxue, or the school of Heart. Records said that, in a place called Longchang in southwestern China, Wang Yangming utilized the rational perception method to discover that the factor behind the dynamics of yin and yang, which he determined was the heart and the mind: the zero-dimension (Wang, 2015). He believed that the mind of the Universe, the myriad things, and humans were the same being sharing the same form (Wang, 2015). Thus, there were no obstacles to communicate with each other.

\section{Discussion}

In the perception of the Universe, the most prominent theories that heavy influenced the path of modern science were the theory of relativity and the M-theory.

Professor Einstein, the great scientist that discovered the theory of relativity perfectly explained the laws for the existence of all substances in the Universe, and he explained the mass-energy conversion law for substances with extreme kinetic energy conditions using the kinetic energy principle of matter and light as the medium (Einstein, Melt Weltbild (Chinese Version), 2018). Perhaps physicists can go beyond the current scope and discover other types of theory of relativity under extreme conditions in electromagnetic or thermal energy, and they will then discover that the fundamental of the Universe lies in the relative conversion of energy with Intelligent Energy as the dynamic source.

Professor Witten, a great mathematician and the founder of M-theory, calculated eleven dimensions out of three-dimensional matters, with time as the fourth dimension (Witten, 1995). The M-theory quickly became a mainstream theory on the Essence of the Universe that even Professor Hawking gave high praise to it and believed it was the ultimate theory in his works The Grand Design (Hawking, 2011). The M-theory has played an immeasurable role in guiding the research on matters, but it is not a physic or cosmology theory. However, at this moment, only the zero and three dimensions exist in the Universe, and scientist has yet to discover and confirm the existence of higher-dimensional space.

In a philosophical perspective, both Eastern and Western philosophers throughout history had tried to explore and explain the Essence of the Universe.

The Eastern philosophy system has a much simpler structure. Subject wise, it has more specifically focused on space-time exploration throughout the ancient time, the Axial Age, and modern time. With previous studies bridging theories in modern physics, such as the theory of relativity, quantum mechanics, and modern astrophysics, to Eastern philosophy, it is possible to reflect and to argue, from a philosophical perspective, on the Essence of the Universe (Liu, 2017; Liu, 2020a). 
In comparison, the Western philosophy system is large and sophisticated, and it contains numerous factions that are independent of each other. On the question of time and space, Leibniz was against the idea of an absolute space proposed by Newton, and once refuted the theory of absolute space using a description of the absolute space in his correspondence with Samuel Clarke (Leibniz, 2000). However, very few studies following the ideologies proposed by Leibniz are found, and the only information available on space-time in the field of philosophy are the few pieces of information left by philosophical sages from Ancient Greece (Liu, 2020d). For example, Plato (427-347 BC) from Ancient Greece believed that the Universe had a chaotic stage, but he has not further explored this theory. Instead, Plato proposed a single principal designer of the Universe, that is God.

\section{The Essence of the Universe}

Liu proposed a new hypothesis, in which the Essence of the Universe and humankind is the zero-dimensional space. In this theory, the Universe is a zero-dimensional matrix filled by zero-dimensional energy. Fundamental and Intelligent Energy, in turn, becomes the $0^{+}$and $0^{-}$in the newly proposed space. The existence of these two distinct energies corresponds to the concept of yin and yang, a manifestation of the reaction and dynamic of yin and yang or, simply put, nature (Legge, 1899; Wang, 2002). However, the relationship between the existence and the dynamic of yin and yang is not merely a bilateral relationship between $\mathrm{A}$ and $\mathrm{B}$, but rather a process of generation-inhibition relationship between wuxing, or the five conceptual elements of metal, water, wood, fire, and earth (Legge, 1899; Legge, 1891a; McDonald, 1996). The proposed relationship of wuxing in regard to the cycle of matters and energy in the Universe is as follows: dynamic $\rightarrow$ balance $\rightarrow$ disruption $\rightarrow$ dynamic $\rightarrow$ balance (Liu, 2020b). This relationship of wuxing is similar to the theory of spontaneous symmetry breaking and parity nonconservation in quantum mechanics, and their similarities are worth exploring scientifically (Gorshkov, Labzovskij, \& Moskalev, 1979; Gribbin, 2019; Earman, 2004; Khriplovich, 1991).

To fully understand space, it requires true knowledge of the void and not some games of language, words, or numbers. However, because humans can only transmit information using language, writings, and numbers as carriers, scholars were forced to express their understanding of space using these means. In previous work, Liu proposed two specific energies trying to describe the four and five-dimensional Universe, namely the four-dimensional Fundamental Energy and the five-dimensional Intelligent Energy, following M-theory's reasoning (Liu, 2020c). These two spatial forms of $q i$ were all part of the existence of the taichi of yin and yang, which filled the zero-dimensional cosmic space. These two forms also correspond to the taichi concept of yin and yang because one existed in the zero-dimensional void while the other was visible three-dimensional matters. In the visible world, these $q i$ further divides into three-dimensional physical forms and the intangible soul of substances, which gave a soul to every 
matter and formed the basis and dynamic of their motion and changes. In the Universe, everything has a soul, and each can perceive and create information for others to perceive thanks to the innate ability to perceive its surrounding. In addition to this passive perceptive system, humankind has the active perception, a better and more capable system that allows humans to perceive the aggregation, growth, existence, and dissipation of all three-dimensional energy and substances.

A similar concept existed in ancient Greek philosophy, proposed by Thales of Miletus (c. 624-547 BC). Thales said that that all things were full of god (Thilly, 1914). He believed that the entire Universe was alive and that even common substances such as rocks had souls, and it was the soul that rendered the Universe lively (Thilly, 1914).

In Eastern philosophy, this concept was discussed in numerous instances. For example, in Wenzi's complement to Laozi's concept, Wenzi narrated that "Yin and yang mold myriad beings; all of them are born of one energy" (Cleary, 1992). Here, Wenzi believed that the qi of yin and yang filled the zero-dimensional void in the Universe, which can correlate to the creation of all the natural substances in the Universe by a combination of Intelligent and Fundamental Energy.

In terms of the communication between humans and the Universe, Zhuangzi summarized a method called Zuowang (坐忘 to sit and forget everything). This method exhibited beneficial to the well-being of the practitioner because it would allow the person's mind to relax and put down any desires and concepts of substances (Liu, 2020c). It is recommended to practice Zuowang in a serene environment such that the person can discard any connection with the active perception to only feel the word with his passive perception (Liu, 2020c; Porter, 2018). Zuowang can then help the individual to allow his body, the most sophisticated information preceptor, to fully enter a state of total automated control in order to cleanse any waste information and substances that the body created during the waking state and to automatically repaired any defects within the body to maintain the well-being of the individual. Meanwhile, the individual could communicate with the zero-dimensional Universe through his mind and spirit because these were equally zero-dimensional, thus connecting the individual with the Universe and renders them together as one. Liu described this method of meditation as the rational perception (Liu, 2020b).

\section{The Essence of Substances}

In recognition of substances, the concept of modern mathematical geometry perfectly exhibited the existence of three-dimensional substances, as shown in Figure 2. But this coordinate system did not yet exist during the time of Zhuangzi.

Zhuangzi gave the name liuhe (六合, the six dimensions) to the outside shape of substances, representing the six directions: front, back, left, right, top, and bottom (Legge J., 1891a). He believed that the appearance of any substances could be described using liuhe (three dimensions). In ancient China, there was a 


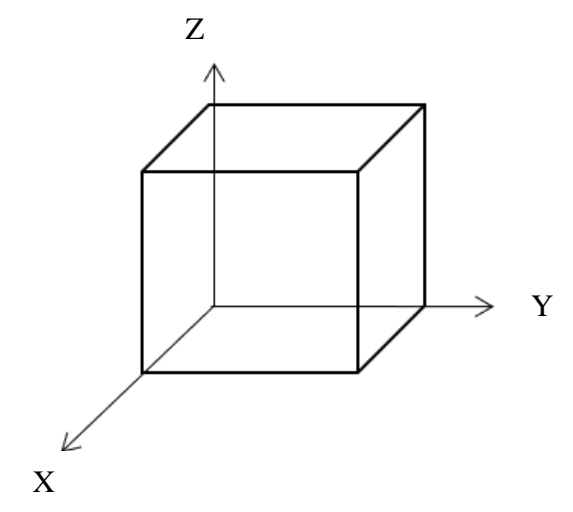

Figure 2. Three-dimensional Coordinates.

prominent belief in a circular Heaven and flat Earth (天圆地方) (Legge, 1891b). However, the true meaning of this statement was that Heaven (the Universe or dao) is the Void and circular. The word "circular" here did not describe the shape, but the symbol $\mathrm{O}$ represented the dao. The word flat, or 方, meant that the Earth is concrete, has directions, and is three-dimensional. This word meant direction, where the myriad things in the Universe, including humans, had their shapes extend toward the six directions. This culture of Heaven, Earth, and humans remained the core of Oriental knowledge throughout its philosophical history.

In comparison, in ancient Greece, Plato proposed the geometrical shape for four classic elements, which he associated fire with the tetrahedron, air with the octahedron, the earth with the cube, and water with the icosahedron. However, regardless of the numbers of faces on the geometrical shape, it was based on the framework of the hexahedron, or the cube, and it was the Western equivalent to the Chinese liuhe. If a polyhedron has an infinite number of faces, correspondingly, it has an infinite amount of he (directions). The only exception to this rule is the circle $\mathrm{O}$, represented by the number $\pi$, an infinitely existing number. Therefore, Zhuangzi believed that there exists only a void (zero-dimensional space) and three-dimensional substances (Legge, 1891a).

Yet, beings exist in the Universe. The first form of $q i$, taix $u$, proposed by Zhuangzi, led to the associating of the concept of being proposed by ancient Greek philosopher Parmenides (c. 515-c. mid-5 ${ }^{\text {th }}$ century BC) and the reminder of a reminiscence to the energy-mass equivalence equation $E=m c^{2}$ of Albert Einstein (Einstein, Mein Weltbild (Chinese Version), 2018; Thilly, 1914). The second form of $q i$ proposed by Zhuangzi was a three-dimensional being called matter (Legge, 1891a). Matters, from particles to atoms to molecules, the myriad things, planets, galaxies, stars, and black holes, were all part of this second form of $q i$, which is the condensed form that exists in the Universe as visible matters.

In modern times, physics had achieved tremendously in cosmologies and chaos theory, and discovered numerous exotic particles such as bosons, fermions, and even the God particle, and compared with the ancient Liezi's notions 
of $q i$, xing (shape), and $z h i$ (substance), the similarities were striking. Therefore, comparing the four stages described by Liezi with current research in quantum mechanics might bring lights to new inspirations to scientists.

The four-dimensional spacetime in Einstein's theory of relativity described the conversion process between energy and mass of matter (Fundamental Energy). This process was a physics' process and not cosmological. The theory of relativity described the relative change and laws of existence for three-dimensional matters within a zero-dimensional space. Forces within this space were information that described substances space contained, and not a curvature in spacetime. Since time is a parameter that describes the existence of substances in space and it is intangible, therefore it cannot be curved.

This ideology was the source of inspiration for the conclusion drawn in Liu's previous works: that the zero-dimensional Intelligent Energy exist in a changeless form within matters and humans and served as the leading function in the creation, perception, and the dealing of yin yang contradiction (Liu, 2020c; Liu, 2020d). This being, in the zero-dimensional void, is called Intelligent Energy, or the source of the dynamic of the entire Universe (Liu, 2020c). It became the cause and the information when it formed three-dimensional substances. The principal reason for the aggregation of the cause was the mind, and it could be found in all, including the Universe, myriad things, and humans. However, only humans' minds contained subjective consciousness that commanded humans to think, create, and act and have made humans an intelligent creature (Liu, 2020b).

\section{Conclusion}

This work studied how the Chinese Oriental knowledge throughout history had explored and perceived the Essence, existence, and dynamic of the Universe. A new hypothesis was also proposed, where, instead of a multi-dimensional Universe as postulated in the M-theory, in reality, the Universe only had a zero-dimensional space containing three-dimensional matters. Numerous references based on Chinese philosophy works throughout history supported this hypothesis. However, like any existential philosophy theory, it needs only the interpretation by modern physics.

This work was based on philosophies and is open to discussion and correction.

\section{Conflicts of Interest}

The authors declare no conflicts of interest regarding the publication of this paper.

\section{References}

Allen, R. (2013). History of Philosophy (Chinese Version) (H. Liu, Trans.). Beijing: New World Press.

Cleary, T. (1992). Wen-Tzu Understanding the Mysteries. Boston, MA \& London: Shambhala. 
Earman, J. (2004). Curie's Principle and Spontaneous Symmetry Breaking. Curie's Principle and Spontaneous Symmetry Breaking, 18, 173-198.

https://doi.org/10.1080/0269859042000311299

Einstein, A. (2018). Mein Weltbild (Chinese Version) (Z. Fang, Trans.). Beijing: CITIC Press.

Gorshkov, V., Labzovskij, L., \& Moskalev, A. (1979). Space and Time Parity Nonconservation Effects in the Diatomic Molecule Spectra. Zhurnal Ehksperimental'noj i Teoreticheskoj Fiziki, 76, 414-421.

Graham, A. (1990). The Book of Lieh-Tzu: A Classic of Tao. New York: Columbia University Press. https://doi.org/10.7312/grah93146

Gribbin, J. (2019). In Search of Schrödinger's Cat: Quantum Physics and Reality (Chinese Version) (G. Zhang, Trans.). Haikou: Hainan Publishing House.

Hawking, S. (2011). The Grand Design (Chinese Version) (Z. Wu, Trans.). Changsha: Hunan Science \& Technology Press Co., Ltd.

Hu, S. (2012). Syllabus to the Chinese Philosophy History (Chinese Version). Beijing: Zhonghua Book Company.

Jaspers, K. (1953). The Origin and Goal of History (M. Bullock, Trans.). New Haven, CT: Yale University Press.

Khriplovich, I. (1991). Parity Nonconservation in Atomic Phenomena. New York: Gordon and Breach Science Publishers.

Laozi. (2015). Dao De Jing (Chinese Version) (W. Gao, Trans.). Beijing: Beijing United Publishing.

Legge, J. (1891a). The Writings of Chuang Tzu. Oxford: Oxford University Press.

Legge, J. (1891b). The Texts of Taoism. Oxford: Oxford University Press.

Legge, J. (1899). The Sacret Books of China the I Ching. New York: Dover Publications Inc.

Leibniz, G. W. (2000). Leibniz and Clarke: Correspondence. London: Hackett Pub Co. Inc.

Liu, S. (2017). Revelation and Reflection on Mankind by Modern Physics Part I. Open Journal of Philosophy, 7, 435-447. https://doi.org/10.4236/ojpp.2017.74023

Liu, S. (2020a). Philosophical Reflection over the Origin of the Universe. Philosophy Study, 10, 213-222.

Liu, S. (2020b). The Essence of the Universe and Humankind. Open Journal of Philosophy, 10, 316-330. https://doi.org/10.4236/ojpp.2020.103021

Liu, S. (2020c). Reflections and Research on the Origin of the Universe (Chinese Version). Taiwan: Warmth Publications.

Liu, S. (2020d). Thinking and Research on the Origin of Humans (Chinese Version). Taiwan: Warmth Publications.

McDonald, J. (1996). Tao Te Ching: An Insightful and Modern Translation.

Porter, B. (2018). Road to Heaven-Encounters with Chinese Hermit (Chinese Version) (J. Ming, Trans.). Chengdu: Sichuan Literature \& Art Publishing House.

Thilly, F. (1914). A History of Philosophy. New York: H. Holt and Company.

Wang, B. (2002). Yellow Emperor's Canon of Internal Medicine (English and Chinese Version) (L. Wu, \& Q. Wu, Trans.). Beijing: China Science and Technology Press.

Wang, S. (2015). Instructions for Practical Living (Chinese Version) (J. Zhang, Ed.). Nanjing: Jiangsu Phoenix Literature and Art Publishing Ltd. 
Witten, E. (1995). String Theory Dynamics in Various Dimensions. Nuclear Physics B, 443, 85-126. https://doi.org/10.1016/0550-3213(95)00158-O

Zhang, Z. (1978). Collection of Zhang Zai (Chinese Version) (X. Zhang, Ed.). Beijing: Zhonghua Publishing House.

Zhu, X. (2020). Original Connotations of Yi (Chinese Version) (T. Zheng, Ed.). Beijing: Jiuzhou Press. 